\title{
ANEMIA PADA KEHAMILAN SEBAGAI FAKTOR RISIKO PERDARAHAN POSTPARTUM DI RUMAH SAKIT
}

\author{
Oktaviani *)
}

\author{
Email: oktaviani.poltekkes@gmail.com
}

\begin{abstract}
Abstrak
Anemia merupakan salah satu faktor risiko perdarahan postpartum. Perdarahan postpartum jika tidak tertangani dengan baik, kasus ini meningkatkan kematian maternal. Berdasarkan data ruang kebidanan RSUD dr. Doris Sylvanus Palangka Raya, jumlah kasus tahun 2010 berjumlah 15 kasus mengalami peningkatan menjadi 40 kasus pada tahun 2011, tahun 2012 berjumlah 34 kasus, dan tahun 2013 jumlah 24 kasus dan tahun 2014 berjumlah 18 kasus. Tujuan penelitian untuk menganalisis hubungan anemia pada kehamilan dengan perdarahan postpartum. Rancangan penelitian ini case control. Sampel kasus penelitian ini adalah ibu bersalin dengan diagnosa perdarahan postpartum berjumlah 44 responden. Kelompok kontrol adalah ibu bersalin yang tidak mendapatkan diagnosa perdarahan postpartum berjumlah 44 responden. Analisis univariat dengan distribusi frekuensi, analisis bivariat dengan chi-square. Hasil penelitian menunjukkan anemia pada kehamilan $(\mathrm{p}=0,00)$ ada hubungan bermakna dengan perdarahan postpartum. Variabel lain usia ibu $(p=0,02)$, paritas $(\mathrm{p}=0,00)$, retensio plasenta $(\mathrm{p}=0,00)$ dan induksi persalinan $(\mathrm{p}=0,00)$ ada hubungan bermakna dengan perdarahan postpartum. Spasing $(\mathrm{p}=0,23)$ dan riwayat perdarahan postpartum $(\mathrm{p}=0,31)$ tidak ada hubungan dengan perdarahan postpartum. Simpulan anemia pada kehamilan ada hubungan bermakna dengan perdarahan postpartum. Usia ibu, paritas, retensio plasenta dan induksi persalinan faktor lain berhubungan dengan perdarahan postpartum.
\end{abstract}

Kata kunci: Anemia Pada Kehamilan, Perdarahan postpartum

*) Dosen Prodi DIII Kebidanan Poltekkes Kemenkes Palangka Raya 


\begin{abstract}
Anemia is one of the risk factors for postpartum hemorrhage. Ff not handled properly, this case increases maternal deaths. Based on the of maternity room data of dr. Doris Sylvanus Palangkaraya, the number of cases in $2010(n=15)$ increased in $2011(n=40)$. Nevertheless, the number of cases has decrease respectively, as in in $2012(n=34), 2013(n=24)$, and in 2014 (18). The aim of the study was to analyze the association of anemia in pregnancy with postpartum hemorrhage.

The study design is case control. The sample of this research case was maternal mother with diagnosis of postpartum hemorrhage amounted to 44 respondents. The control group was a maternal mother who did not get a diagnosis of postpartum hemorrhage amounting to 44 respondents. Univariate analysis with frequency distribution, bivariate analysis with chi-square.

The results showed anemia in pregnancy $(p=0,00)$ there was a significant relationship with postpartum hemorrhage. Other variables of maternal age $(p=0.02)$, parity $(p=0.00)$, placental retention $(p=0.00)$ and induction of labor $(p=0.00)$ there was a significant association with postpartum hemorrhage. Spacing $(p=0.23)$ and history of postpartum hemorrhage $(p=0.31)$ had no association with postpartum hemorrhage. It is conclude that anemia in pregnancy has a significant association with postpartum hemorrhage. Maternal age, parity, placental retention and labor induction of other factors are associated with postpartum hemorrhage.
\end{abstract}

Keyword: Anemia in pregnancy, Haemoragic Postpartum 


\section{Pendahuluan}

Salah satu penyebab utama kematian ibu di negara berkembang dan $25 \%$ penyebab kematian ibu di dunia adalah perdarahan postpartum. Perdarahan postpartum adalah perdarahan yang melebihi $500 \mathrm{cc}$ pada persalinan pervaginam dan melebihi $1000 \mathrm{cc}$ pada persalinan secara sectio caesaria setelah kelahiran bayi (Evensen A \& Anderson J, 2013). Renjatan karena perdarahan banyak pada persalinan segera akan berdampak fatal bagi ibu, yang dapat menyebabkan anemia sehingga daya tahan ibu berkurang, serta syok hemorragic. Selanjutnya, apabila keadaan tidak dapat diatasi secara cepat dan tepat oleh tenaga yang terampil dan fasilitas pelayanan kesehatan yang memadai dapat menyebabkan kematian maternal (Manuaba, 2012).

Menurut Evensen A \& Anderson J (2013), salah satu faktor risiko perdarahan postpartum adalah anemia pada kehamilan. Badr Safaa, dkk (2015) menyatakan bahwa anemia pada masa kehamilan merupakan faktor risiko potensial yang berhubungan dengan perdarahan postpartum. Anemia pada kehamilan meningkatkan risiko perdarahan postpartum. Semakin rendah kadar haemoglobin Ibu semakin besar risiko mengalami perdarahan postpratum (Frass Kaima A., 2015).

Badan Layanan Umum Daerah Rumah Sakit Umum Daerah dr Doris Sylvanus merupakan salah satu fasilitas pelayanan kesehatan di kota Palangka Raya dan merupakan rumah sakit rujukan di Provinsi Kalimantan Tengah. Berdasarkan data register di Ruang kebidanan, kejadian perdarahan postpartum jumlah kasus yang tercatat pada tahun 2009 terdapat 12 kasus, mengalami peningkatan menjadi 15 kasus pada tahun 2010, tahun 2011 berjumlah 40 kasus, tahun 2012 berjumlah 34 kasus, dan pada tahun 2013 jumlah 24 kasus dan tahun 2014 berjumlah 18 kasus (BLUD RSUD dr. Doris Sylvanus Palangka Raya 2010-2014). Penelitian ini bertujuan untuk mengetahui mengetahui hubungan anemia pada kehamilan dan faktor lain dengan perdarahan postpartum di ruang kebidanan BLUD RSUD dr. Doris Sylvanus Palangka Raya.

\section{Metode}

Desain Penelitian ini adalah penelitian case control dengan pendekatan retrospektif, dimana penelitian ini dimulai dengan mengidentifikasi pasien dengan perdarahan postpartum dan pasien tanpa perdarahan postpartum.

Populasi penelitian ini adalah seluruh ibu yang melahirkan di ruang bersalin RS dr. Doris Sylvanus Palangka Raya pada tahun 2014 berjumlah 1149 orang. Sampel pada penelitian ini berjumlah 88 orang dihitung menggunakan rumus kasus control. Kelompok kasus adalah ibu bersalin yang mendapatkan diagnosa perdarahan postpartum di ruang kebidanan BLUD RSUD dr.Doris Sylvanus Palangka Raya berjumlah 44 orang. Kelompok kontrol adalah ibu bersalin yang tidak mendapatkan diagnosa perdarahan postpartum di ruang kebidanan BLUD RSUD dr.Doris Sylvanus Palangka Raya berjumlah 44 orang. Pemilihan sampel dipilih dengan menggunakan consecutive sampling. 


\section{Hasil}

\section{Karakteristik Responden}

Berdasarkan hasil penelitian bahwa Ibu yang anemia paling banyak mengalami perdarahan yaitu sebesar 35,2\% (31). Kelompok usia ibu hamil 20-35 tahun paling banyak mengalami perdarahan yaitu sebesar 34,1\% (30).Ibu hamil dengan paritas multipara (2-4 orang) paling banyak mengalami perdarahan yaitu sebesar $33,0 \%$ (29). Pada variabel spasing, ibu yang mengalami perdarahan pada jarak kehamilan $\geq 2$ tahun sebesar 47,7\% (42). Pada ibu bersalin yang tidak mengalami retensio plasenta paling banyak mengalami perdarahan yaitu sebesar 35,2\% (31). Sedangkan, ibu yang tidak diberikan induksi pada persalinan mengalami perdarahan sebesar $40,9 \%$ (36). Hasil penelitian dapat ditunjukkan pada Tabel 1 di bawah ini:

Tabel 1. Distribusi Karakteristik Responden (n=88)

\begin{tabular}{|c|c|c|c|c|}
\hline \multirow{3}{*}{ Variabel } & \multicolumn{4}{|c|}{ Perdarahan Postpartum } \\
\hline & \multicolumn{2}{|c|}{$\begin{array}{c}\text { Ya } \\
(n=44)\end{array}$} & \multicolumn{2}{|c|}{$\begin{array}{c}\text { Tidak } \\
(n=44)\end{array}$} \\
\hline & $\mathbf{N}$ & $\%$ & $\mathbf{n}$ & $\%$ \\
\hline \multicolumn{5}{|l|}{ Anemia } \\
\hline$-\quad \mathrm{Ya}$ & 31 & $35,2 \%$ & 10 & $11,4 \%$ \\
\hline - $\quad$ Tidak & 13 & $14,8 \%$ & 34 & $38,6 \%$ \\
\hline \multicolumn{5}{|l|}{ Umur } \\
\hline$-<20$ tahun & 2 & $2,3 \%$ & 8 & $9,1 \%$ \\
\hline - $20-35$ tahun & 30 & $34,1 \%$ & 32 & $36, \$ \%$ \\
\hline$-\quad>35$ tahun & 12 & $13,6 \%$ & 4 & $4,5 \%$ \\
\hline \multicolumn{5}{|l|}{ Paritas } \\
\hline - Primipara & 11 & $12,5 \%$ & 24 & $27,3 \%$ \\
\hline - Multipara & 29 & $33,0 \%$ & 20 & $22,7 \%$ \\
\hline - Grandemultipara & 4 & $4,5 \%$ & 0 & $0 \%$ \\
\hline \multicolumn{5}{|l|}{ Spasing } \\
\hline$-\quad<2$ tahun & 2 & $2,3 \%$ & 5 & $5,7 \%$ \\
\hline$-\quad \geq 2$ tahun & 42 & $47,7 \%$ & 39 & $44,3 \%$ \\
\hline \multicolumn{5}{|l|}{ Riwayat perdarahan } \\
\hline$-\mathrm{Ya}$ & 1 & $1,1 \%$ & 0 & $0 \%$ \\
\hline - Tidak & 43 & $48,9 \%$ & 44 & $50,0 \%$ \\
\hline \multicolumn{5}{|l|}{ Retensio Plasenta } \\
\hline - Ya & 13 & $6,5 \%$ & 0 & $0 \%$ \\
\hline - Tidak & 31 & $35,2 \%$ & 44 & $50,0 \%$ \\
\hline \multicolumn{5}{|l|}{ Induksi Persalinan } \\
\hline - Ya & 8 & $9,1 \%$ & 0 & $0 \%$ \\
\hline - Tidak & 36 & $40,9 \%$ & 44 & $50,0 \%$ \\
\hline
\end{tabular}

\section{Anemia Pada Kehamilan dengan Perdarahan Postpartum}

Hasil uji chi square menunjukkan bahwa anemia pada kehamilan nilai $\mathrm{p}<0,05$, hal ini menyatakan bahwa anemia pada kehamilan terdapat hubungan bermakna terhadap perdarahan postpartum $(\mathrm{p}=0,00)$. Hasil analisis ditunjukkan pada Tabel 2 berikut ini: 
Tabel 2. Hubungan Anemia pada Kehamilan dengan Perdarahan Postpartum (n=88)

\begin{tabular}{|c|c|c|c|c|c|c|}
\hline \multirow{3}{*}{ Variabel } & \multicolumn{4}{|c|}{ Perdarahan Postpartum } & \multirow[t]{3}{*}{$\mathbf{P}$} & \multirow[t]{3}{*}{ OR (IK 95\%) } \\
\hline & \multicolumn{2}{|c|}{$\begin{array}{c}Y a \\
(n=44)\end{array}$} & \multicolumn{2}{|c|}{$\begin{array}{c}\text { Tidak } \\
(\mathrm{n}=44)\end{array}$} & & \\
\hline & $\mathbf{N}$ & $\%$ & $\mathbf{N}$ & $\%$ & & \\
\hline Anemia & & & & & $0,00^{*}$ & 8,10 \\
\hline$-\quad \mathrm{Ya}$ & 31 & $35,2 \%$ & 10 & $11,4 \%$ & & $(3,11-21,11)$ \\
\hline - Tidak & 13 & $14,8 \%$ & 34 & $38,6 \%$ & & \\
\hline
\end{tabular}

Keterangan: nilai $p$ dihitung dengan uji chi square

\section{Hubungan Variabel lain dengan}

\section{Perdarahan Postpartum}

Berdasarkan hasil uji chi square menunjukkan bahwa variabel usia, paritas, retensio plasenta dan induksi persalinan terdapat hubungan

Sedangkan, pada variabel spasing dan riwayat perdarahan menunjukkan tidak ada hubungan bermakna dengan perdarahan postpartum. bermakna dengan perdarahan postpartum.

Tabel 3. Hubungan Variabel Lain dengan Perdarahan Postpartum $(n=88)$

\begin{tabular}{|c|c|c|c|c|c|c|}
\hline \multirow{3}{*}{ Variabel } & \multicolumn{4}{|c|}{ Perdarahan Postpartum } & \multirow[t]{3}{*}{$\mathbf{P}$} & \multirow[t]{3}{*}{ OR (IK 95\%) } \\
\hline & \multicolumn{2}{|c|}{$\begin{array}{c}\text { Ya } \\
(n=44)\end{array}$} & \multicolumn{2}{|c|}{$\begin{array}{c}\text { Tidak } \\
(n=44)\end{array}$} & & \\
\hline & $\mathbf{N}$ & $\%$ & $\mathbf{n}$ & $\%$ & & \\
\hline Usia & & & & & $0,02 *$ & $0,83(0,12-0,56)$ \\
\hline$-<20$ tahun & 2 & $2,3 \%$ & 8 & $9,1 \%$ & & $0,31(0,91-1,07)$ \\
\hline - 20 - 35 tahun & 30 & $34,1 \%$ & 32 & $36, \$ \%$ & & \\
\hline$->35$ tahun & 12 & $13,6 \%$ & 4 & $4,5 \%$ & & \\
\hline Paritas & & & & & $0,00^{*}$ & $3,1(1,26-7,88)$ \\
\hline - Primipara & 11 & $12,5 \%$ & 24 & $27,3 \%$ & & \\
\hline - Multipara & 29 & $33,0 \%$ & 20 & $22,7 \%$ & & \\
\hline - $\quad$ Grandemultipara & 4 & $4,5 \%$ & 0 & $0 \%$ & & \\
\hline Spasing & & & & & 0,23 & $0,37(0,68-2,02)$ \\
\hline$-<2$ tahun & 2 & $2,3 \%$ & 5 & $5,7 \%$ & & \\
\hline$-\quad \geq 2$ tahun & 42 & $47,7 \%$ & 39 & $44,3 \%$ & & \\
\hline Riwayat perdarahan & & & & & 0,31 & $0,49(0,40-0,61)$ \\
\hline$-\mathrm{Ya}$ & 1 & $1,1 \%$ & 0 & $0 \%$ & & \\
\hline - Tidak & 43 & $48,9 \%$ & 44 & $50,0 \%$ & & \\
\hline Retensio Plasenta & & & & & $0,00^{*}$ & $0,41(0,31-0,54)$ \\
\hline - Ya & 13 & $6,5 \%$ & 0 & $0 \%$ & & \\
\hline - Tidak & 31 & $35,2 \%$ & 44 & $50,0 \%$ & & \\
\hline Induksi Persalinan & & & & & $0,00^{*}$ & $0,45(0,35-0,57)$ \\
\hline - Ya & 8 & $9,1 \%$ & 0 & $0 \%$ & & \\
\hline - Tidak & 36 & $40,9 \%$ & 44 & $50,0 \%$ & & \\
\hline
\end{tabular}

Keterangan: nilai $p$ dihitung dengan uji chi square 


\section{Pembahasan}

\section{Anemia Pada Kehamilan dengan Perdarahan Postpartum}

Dari hasil uji chi square pada penelitian ini variabel anemia ditemukan ada hubungan bermakna dengan kejadian perdarahan postpartum ibu bersalin. Penelitian ini sejalan dengan hasil penelitian Ramanathan G (2006) dan Evensen Ann et all (2013) menyatakan bahwa ibu hamil dengan anemia merupakan salah satu faktor risiko ibu bersalin mengalami perdarahan postpartum. Hasil penelitian ini juga menemukan bahwa Ibu yang mengalami anemia akan berisiko mengalami perdarahan postpartum 8,1 kali lebih tinggi dibandingkan ibu yang tidak mengalami anemia. Hasil penelitian Prata Ndola, dkk (2011) juga melaporkan ibu yang mengalami anemia akan meningkatkan risiko ibu mengalami perdarahan postpartum 2,73 kali lebih tinggi dibandingkan ibu yang tidak anemia.

Anemia merupakan suatu keadaan yang dimana kadar hemoglobin lebih rendah dari batas normal $11 \mathrm{~g} / \mathrm{dl}$ untuk kelompok ibu hamil dan ibu bersalin. Ibu hamil yang mengalami anemia dapat mengurangi daya tahan tubuh ibu dan meninggikan frekuensi komplikasi kehamilan serta persalinan. Selain itu, juga menyebabkan peningkatan risiko perdarahan pasca persalinan. Rasa cepat lelah pada penderita anemia disebabkan metabolisme energi oleh otot tidak berjalan secara sempurna karena kekurangan oksigen (Manuaba, 2012). Semakin rendah kadar $\mathrm{Hb}$ Ibu hamil atau semakin berat anemia yang dialami, maka semakin meningkatkan risiko mengalami perdarahan postpartum (Frass Kaima A, 2015). Risiko perdarahan postpartum meningkat pada ibu bersalin dengan anemia berat, hal ini disebabkan karena uterus kekurangan oksigen, glukosa, nutrisi essensial dan tidak bekerja efesien pada saat persalinan. Akibat kurangnya jumlah oksigen yang diikat dalam darah menyebabkan otot-otot uterus tidak berkontraksi secara adekuat sehingga timbul atonia uteri yang mengakibatkan perdarahan postpratum (Cuninngham, 2013).

\section{Faktor Risiko Lain dengan Perdarahan}

\section{Postpartum}

Pada penelitian ini hasil uji chi square variabel usia ibu menunjukkan bahwa ada hubungan bermakna dengan perdarahan postpartum pada ibu bersalin. Hasil ini menunjukkan bahwa responden yang usia >35 tahun memiliki risiko mengalami perdarahan 0,31 kali lebih tinggi dibandingkan usia 20-35 tahun dan $<20$ tahun. Penelitian Kramer MS dkk (2013) juga melaporkan hal yang sama usia ibu faktor risiko yang berhubungan dengan kejadian perdarahan postpartum dan usia ibu >35 tahun memiliki risiko 1,5 kali mengalami perdarahan postpartum.

Hasil penelitian Dina D, dkk (2014) di RSUD Majene juga melaporkan bahwa usia ibu >35 tahun memiliki risiko mengalami perdarahan postpartum 3,1 kali lebih besar dibandingkan usia 20-25 tahun. Manuaba (2012) mengemukakan bahwa pada usia diatas 35 tahun fungsi reproduksi seorang wanita sudah mengalami penurunan dibandingkan fungsi reproduksi normal sehingga kemungkinan untuk terjadinya komplikasi pascapersalinan terutama perdarahan akan lebih besar. Selain itu, Winkjosastro (2005) menyatakan bahwa risiko perdarahan postpartum primer pada ibu yang berumur $>35$ tahun lebih 
besar dibandingkan dengan ibu yang berumur 2035 tahun.

Hasil uji chi square pada variabel paritas menunjukkan bahwa terdapat hubungan bermakna dengan kejadian perdarahan postpartum pada ibu bersalin. Ibu dengan paritas grandemultipara (>5) memiliki risiko mengalami perdarahan 3,1 kali lebih tinggi dibandingkan paritas primipara dan multipara. Penelitian Dina D, dkk (2014) juga melaporkan bahwa paritas Ibu dengan paritas tinggi mempunyai resiko perdarahan postpartum yang lebih besar akibat atonia uteri, uteri inversi dan sisi konsepsi yang tertinggal dalam uterus. Hal ini terjadi karena tonus kontraksi uterus yang lebih rendah dan tidak cukup kuat. Kalau terjadinya atoni uteri, juga berkemungkinan adanya bekuan darah dalam uterus. Ini menyebabkan miometrium gagal berkontraksi secara menyeluruh untuk memampatkan pembuluh darah yang robek sehingga mencegah perdarahan yang lanjut (Cunningham, 2013).

Pada variabel spasing dengan uji chi square diperoleh hasil tidak ada hubungan bermakna dengan perdarahan postpartum pada ibu bersalin. Hal ini menunjukkan tidak ada perbedaan antara spasing $<2$ tahun dan $\geq 2$ tahun dengan kejadian perdarahan postpartum pada ibu bersalin. Penelitian ini menunjukkan bahwa, ibu hamil yang spasing $<2$ tahun dan $>2$ tahun sama-sam berisiko mengalami perdarahan postpartum. Hasil penelitian Dwi Astuti, dkk juga menyatakan bahwa spasing tidak ada hubungan bermakna dengan perdarahan postpartum.

Hasil uji chi square ditemukan variabel riwayat perdarahan sebelumnya tidak ada hubungan bermakna dengan kejadian perdarahan postpartum. Hasil penelitian ini tidak sejalan dengan penelitian Badr Safaa, dkk (2015) yang menyatakan bahwa riwayat perdarahan postpratum sebelumnya terdapat hubungan bermakna dengan kejadian perdarahan postpartum. Pada penelitian ini tidak terdapat hubungan bermakna, hal ini menunjukkan bahwa ibu hamil walaupun tidak memiliki riwayat perdarahan sbelumnya namun jika mengalami anemia atau hipertensi dalam kehamilan akan berisiko mengalami perdarahan postpartum.

Pada penelitian ini hasil uji chi square variabel retensio plasenta ditemukan ada hubungan bermakna dengan kejadian perdarahan postpartum. Oyelese Y dan Ananth C (2010) menyatakan salah satu faktor penyebab perdarahan pada ibu bersalin adalah retensio plasenta. Penelitian Olowokere AE, dkk (2013) melaporkan retensio plasenta merupakan faktor penyebab terjadinya perdarahan postpartum $(52,4 \%)$. Selain itu, Prata Ndola, dkk (2011) juga melaporkan ibu yang mengalami retensio plasenta akan meningkatkan risiko ibu mengalami perdarahan postpartum 21,68 kali lebih tinggi dibandingkan ibu yang tidak retensio plasenta. Retensio plasenta merupakan suatu keadaan dimana tertahannya atau belum lahirnya plasenta hingga atau lebih dari 30 menit setelah bayi lahir. Hampir sebagian besar gangguan pelepasan plasenta disebabkan oleh gangguan kontraksi uterus (Prawirohardjo S, 2011).

Penelitian ini dari hasil uji chi square menunjukkan terdapat hubungan bermakna dengan kejadian perdarahan postpartum pada ibu bersalin. Hasil ini menunjukkan ada perbedaan 
ibu yang diberikan induksi persalinan dan tidak dengan kejadian perdarahan postpartum. Penelitian Prata Ndola, dkk (2011) melaporkan ibu bersalin dengan induksi persalinan akan berisiko mengalami perdarahan 2,37 kali lebih tinggi dibandingkan ibu yang tidak diinduksi persalinan. Davis Deborah, dkk (2012) juga menemukan bahwa induksi persalinan meningkatkan risiko perdarahan pada ibu bersalin.

\section{Simpulan}

Anemia pada kehamilan merupakan faktor risiko kejadian perdarahan postpartum ibu bersalin. Faktor risiko lain meningkatkan risiko perdarahan postpartum adalah usia Ibu, paritas, retensi plasenta dan induksi persalinan.

\section{Daftar Pustaka}

Badr Safaa, Bilkasem Amenh, Elkhwsky Fayek. 2015. Risk Factor For Primary Postpartum Hemorrage in Benghazi, Libya: A Case Control Study. Scholar Journal of Applied Medical Sciences. 3(1C).

BLUD RSUD dr. Doris Sylvanus Palangka Raya. 2014. Register Ruang Kebidanan. BLUD RSUD dr. Doris Sylvanus Palangka Raya

Cunningham, F. G., Gant, N. F., Leveno, K. J., Giltrap, L. C., Hauth, J. C., Wenstrom, K. D. (2013) Williams obstetrics 23 ed. New York: Mc Graw-Hill

Davis Deborah, Baddock Sally, Pairman Sally, Hunter Marion, Benn Cheryl, Anderson Jacqui, Dixon Lesley, Herbonson Peter. 2012. Risk of Severe Postpartum Hemorrage in Low-Risk Chlidbering Women in New Zealand:Exploring the Effect of Place of Birth and Comparing Third Stage Management of Labor. Birth 39(2)

Dina Darmin, Seweng Arifin, Nyorong Mappeaty. 2014. Faktor Determinan kejadian Perdarahan Postpartum di RSUD Majene Kabupaten Majene. www.pasca.unhas.ac.id. diakses tanggal 15 Desember 2015
Astuti Dwi K, Mifbakhuddin, Meikawati Wulandari. 2013. Faktor Risiko Perdarahan Pasca Persalinan (Studi di RSUP Dr. Kariadi Semarang). http://digilib.unimus.ac.id

Evensen A, Anderson. 2013. Postpartum hemorrage: third stage pregnancy. www.aafp.org diakses tanggal 8 desember 2014

Frass A. Kaima. 2015. Postpartum Hemorrhage is Related to the Hemoglobin levels at labor: Observasional Study. Alexandria Journal of Medicine (51)

Guyton, A.C., Hall, J.E., 1997. Buku Ajar Fisiologi Kedokteran. Edisi 9. Jakarta: EGC.

Jekti Pangerti R, Suarthana E. 2011. Risk factor of postpartum haemorrage in Indonesia. Health science Indonesia (2)

Kramer MS, Berg C, Abenhaim H, Dahhou M, Rouleau J, Mehrabadi A Joseph KS. 2013. Incidence, risk factor and temporal trends in severe postpartum hemorrage. American journal of obstetric \& gynecology 209:449

Kementerian Kesehatan RI. 2013. Profil kesehatan Indonesia. Jakarta

Manuaba, I.G.B. 2012. Pengantar kuliah obstetri. Jakarta: Trans Info Media.

Olowokere AE, Adekeye OA, Ogunfowokan A, Olagunju OE, Irinoye OO. 2013. The Prevalence, Management and Outcome of Primary Postpartum Haemorrage in Selected Health Care Facilities in Nigeria. Academic Journal vol 5(3)

Oyelese YMD, Ananth CV. 2010. Postpartum haemorrage: epidemiology, risk factor and causes. Clinical Obstetric and Gynecology 53(I)

Prawirohardjo, Sarwono. 2011. Ilmu Kebidanan. Jakarta : YBP-SP.

Prata Ndola, Hamza Sabry, Bell Suzanne, Karasek Deborah, Vahidnia Famaz, Holston Martine. 2011. Inability to Predict Pospartum Hemorrage: Insights from Egyptian Intervention Data. MMC Pregnancy and Childbirth 11(97)

Ramanthan G, Arulkumaren S. 2006. Postpartum Haemorrage. JOGC 28(11)

Ruang Kebidanan BLUD RSUD dr. Doris Sylvanus Palangka Raya. 2013, 2014. Laporan Register Ruang Kebidanan. Palangka Raya.

Winkjosastro. 2005. Ilmu Bedah Kebidanan. Jakarta: Yayasan Bina Pustaka Sarwono Prawirohardjo 
